Chapter 8

\title{
Human Papillomavirus Infection and Penile Cancer: Past, Present and Future
}

João Paulo Oliveira-Costa, Giórgia Gobbi da Silveira,

Danilo Figueiredo Soave,

Andrielle de Castilho Fernandes,

Lucinei Roberto Oliveira, Alfredo Ribeiro-Silva and

Fernando Augusto Soares

Additional information is available at the end of the chapter

http://dx.doi.org/10.5772/55811

\section{Introduction}

Penile squamous cell carcinoma (PSSC) is an uncommon malignant tumor, which accounts for less than $1 \%$ of adult male cancers in North America and Europe, but is markedly higher in developing locations, such as Asia, Africa and South America, representing up to $10 \%$ of tumors in men. Human papillomavirus (HPV) infection has shown an important role in penile cancer pathogenesis. In 2009, a systematic review of published literature found that $40 \%$ of penile tumors were HPV-related, and that type $16 \mathrm{HPV}$ was the most common subtype in this group (Backes et al., 2009). Another interesting relation between HPV infection and penile cancer is the finding that specific histological subtypes are associated with HPV infection. Penile carcinomas with basaloid differentiation and warty features have shown a strong association with HPV infection, with recent studies showing that HPV infection is present in $76 \%$ of basaloid tumors, while the presence in verrucous cancer was $24.5 \%$ (Backes et al., 2009).

The recent literature suggests that the oncogenic potential of HPV integration into host DNA genome and their ability to manipulate cell cycle regulators is responsible for the establishment and maintenance of HPV genomes in the squamous epithelium and HPV-related PSCC cancer, which will result in deregulated expression of oncoproteins such as E6 and E7. The oncoprotein E6 is known to induce degradation of the tumor suppressor protein p53 and the oncoprotein E7 binds to retinoblastoma protein (pRb). Thus, the oncoproteins E6/E7 allow cells to evade 
cell cycle checkpoints and to entrance in S1 phase of cell cycle, leading to disruption of normal cell cycle controls.

Following cell division, infected cells leave the basal layer, migrate towards the suprabasal regions and begin to differentiate. Increased understanding of cervical pathogenesis has led to confirmation of HPV as an etiological agent for several cancers and consequently to the development of preventive vaccines targeting HPV antigens for the control of HPV-related cancers. HPV vaccine was developed as a result of the achievement of core technologies, that are able to produce virus-like particles (VLPs), which, in turn, are able to mimic the natural virus and elicithigh-titers of virus neutralizing antibodies. With the progress through advanced stages of clinical trials and further exploration of combinatorial strategies, there is a great promise for significantadvancesalsoin the field of therapeuticHPV vaccinedevelopment, notonly tocervical cancer, but other several malignancies related to HPV infection. Moreover, in this chapter we discuss the current status of HPV vaccines as well as the most common associated factors that might interfere on establishment of strategies that could control the HPV infections and the development of penile carcinoma associated to this infection.

\section{Penile cancer}

Penile malignancies are thought to arise from the accumulation of multiple mutations that may occur as consequence of progressive genetic instability. This intricate process of genetic instability may be caused by environmental factors, such as history of intense smoking, penile tears, phimosis, and poor genital hygienic habits. (Chaux \& Cubilla 2012). In addition, a recent study conducted by Chaux et al. (2011) also described the poor education, penile chronic inflammation, genital warts and Human papillomavirus (related to number of sexual partners during lifetime) as environmental factors to malignant transformation.

There is a worldwide geographic difference in occurrence of penile malignancies that could be caused by differences in socio-economic status, cultural and religious conditions (Bleeker et al. 2009, Chaux \& Cubilla, 2012). The higher incidences are frequent in tropical or subtropical regions of Latin America, Asia and Africa but have uncommon incidence rates in Europe, Japan, USA and Israel (Cubilla 2009). Recently, were reported higher incidence rates in underdeveloped regions such as Africa, South America, and Asia (2-4/100000 inhabitants) as compared with North America (United States) and Europe (0.3-1/100000 inhabitants) (Chaux \& Cubilla, 2012). Pow-Sang et al. (2010) also described the penile malignancies prevalence rate among different populations. Prevalence rates in developed countries as Israel (0.1/100 000) and United States (0.3-1.8/100 000) and interestingly, compared with underdeveloped countries such as Uganda (2.8/100 000) and Brazil (1.5-3.7/100 000). Once again confirming the disease geographical difference and the influence of country development.

Squamous cell Carcinoma represents vast majority of histological subtype of primary penile malignancies with heterogeneous features due to differences in morphology pathogenesis and prognosis (Hakenberg \& Protzel, 2012; Stankiewicz et al., 2012; Syed et al., 2012). Knowledge 
of origin and progression of penile squamous cell carcinoma depends on an intricate relation between anatomy and histopathology.

The anatomy of the penis is complex and has important implications to define predictive risk model and delineate the prognostic factors (Chaux \& Cubilla, 2012). The same authors described 3 anatomical compartments in the penis (Glans, Foreskin and Coronal Sulcus) where the malignant neoplasms may be originated (Fig 1). However, the penile malignant neoplasms have a predilection to originate first on the Gland followed by Foreskin inner mucosa and lastly the Coronal Sulcus is rarely affected by neoplastic entity.

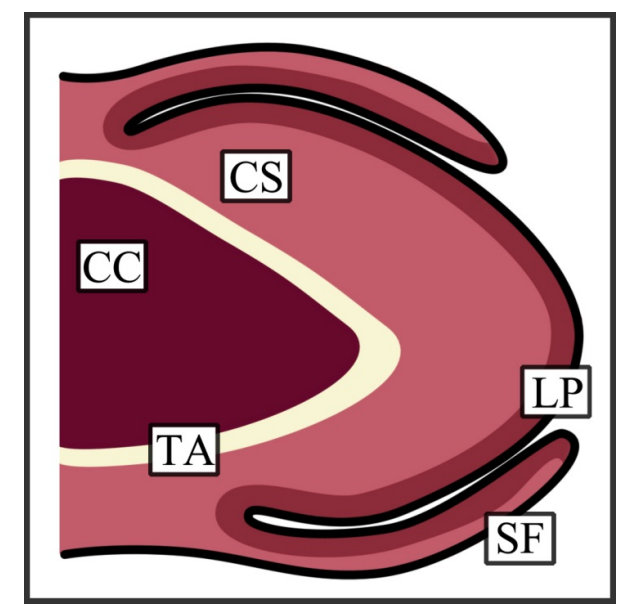

Figure 1. Paraurethral longitudinal section presenting anatomical levels of the Penis. CC: Corpus Cavernosum; CS: Corpus Spongiosum; LP: Lamina Propria; SF: Skim of the Foreskim and TA: Tunica Albuginea. (Adapted from Chaux \& Cubilla 2012).

Recently, Hernandez et al. (2008) performed an epidemiological study with 4967 United States men with the diagnosis of penile squamous cell carcinoma. Thirty four percent of patients (1712) presented neoplasms arising in gland, $13.2 \%$ in prepuce, $5.3 \%$ in penis shaft, $4.5 \%$, in overlapping of penis, and $42,5 \%$ in unspecified site. Lesions generally initiate on the glans and slowly extend to involve completely the glans and shaft of the penis. During the neoplasm progress Buck's fascia act as a natural barrier to local tumor invasion defending the corporal bodies from tumoral expansion (Pow-Sang et al. 2010). This assessment is schematically illustrated in figure 2 .

The anatomy of the penis presents a pivotal role in tumor invasion and prognosis of cancer. Moreover, the TNM staging system is based, at least partially, on the commitment of these anatomical levels (Velazquez et al. 2010). The glans can be divided in 4 levels: squamous epithelium, lamina propria, corpus spongiosum, and corpus cavernosum (corpus spongiosum, and corpus cavernosum are subdivided by the tunica albugínea). Anatomical levels in the foreskin, like in glans, are divided in squamous epithelium, lamina propria, dartos muscle, and outer skin (Chaux \& Cubilla, 2012). 


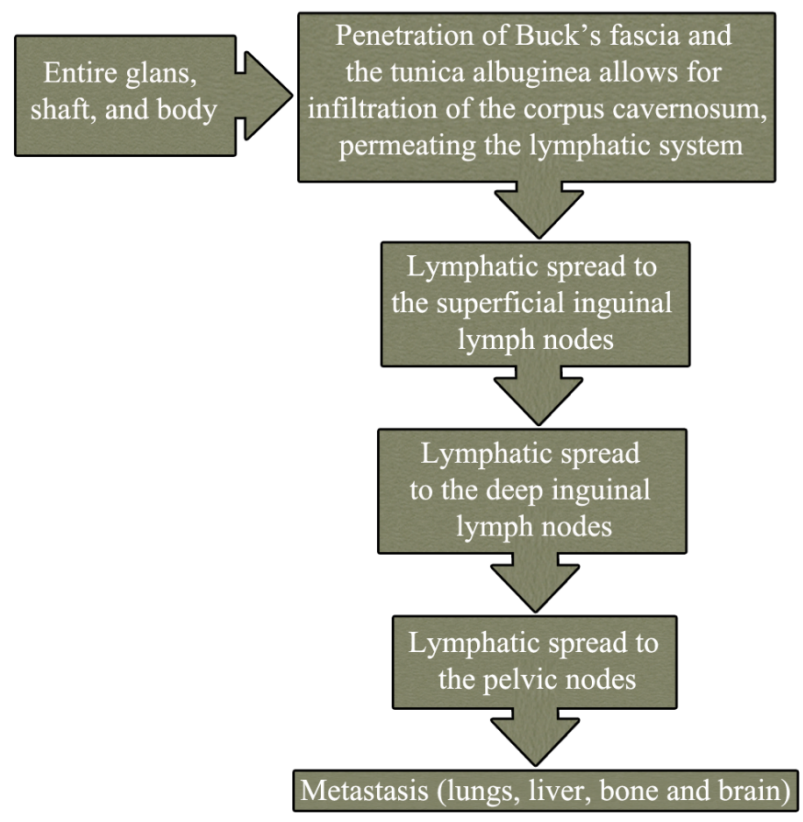

Figure 2. Natural history of penile cancer (Adapted from Pow-Sang et al. 2010).

A previous study suggests that different tumor histological features could be based on anatomical site. This hypothesis is sustained by the histological differences among the urethral segments and their corresponding neoplasms (Velasquez et al. 2005). As discussed previously, Squamous Cell Carcinoma of Usual Type (SCCUT) is the most frequent histopathologic diagnoses in penile malignancies (Chaux \& Cubilla, 2012; Stankiewicz et al. 2012) affecting around $48 \%-65 \%$ of all type of penile carcinoma. Additionally, Epstein et al. (2011) reported 11 more subtypes of SCCUT (Table 1). Macroscopic features of SCCUT range from endophytic to irregular exophytic masses, presenting white-to-gray coloration. However, the reddish pigmentation also can be observed (Chaux et al. 2010). Microscopilly, the SCCUT is similar to oral, vulvar and cervical Squamous Cell Carcinomas (Cubilla et al. 2001). SCCUT may vary from well-differentiated tumors to anaplastic entities. Other presented feature is keratinization, ranging from highly keratinized, presented in well-differentiated tumors, until scarce or minimal keratinization observed in anaplastic neoplasm. Chaux et al. (2010)

Evidences from pertinent literature indicate the involvement of groin lymph nodes as the most relevant and unfavorable prognostic factors predicting cancer-specific survival in patients with penile squamous cell carcinoma. Numerically, in the same review, the 5-year cancerspecific survival rate for those presenting cN0 tumors were between $75 \%$ and $93 \%$, compared with a 5-year cancer-specific survival rate for those presenting $\mathrm{cN} 3$ tumors ranging between $20 \%$ and $34 \%$. There is a substantial decrease in the survival rates with N progression (Novara et al. 2007). 


\begin{tabular}{ll}
\hline & \multicolumn{1}{c}{ Classification of SCCs of the penis } \\
\hline Subtype & Frequency (\%) \\
\hline Usual SCC & $48-65$ \\
\hline Basaloid carcinoma & $4-10$ \\
\hline Warty carcinoma & $7-10$ \\
\hline Verrucous carcinoma & $3-8$ \\
\hline Papillary carcinoma & $5-15$ \\
\hline Sarcomatoid carcinoma & $1-3$ \\
\hline Mixed carcinomas & $9-10$ \\
\hline Adenosquamous carcinoma & $1-2$ \\
\hline Pseudohyperplastic carcinoma & $<1$ \\
\hline Carcinoma cuniculatum & $<1$ \\
\hline Pseudoglandular carcinoma & $<1$ \\
\hline Warty-basaloid carcinoma & $9-14$ \\
\hline
\end{tabular}

Table 1. Classification of Squamous Cell Carcinomas (SCCS) of the penis (Adapted from Chaux \& Cubilla 2012)

Lopes et al. (2002) performed a study that aimed to investigate the p53 in Brazilian patients with PSCC to establish a new prognostic factor for lymph node metastasis and its possible influence on prognosis. This study observed the nodal stage as a factor that influenced survival (independent risk factors) in the univariate and multivariate analyses. Gunia et al. (2012) shown that p16INK4a is a good prognostic marker for penile squamous cell carcinomas, surpassing the prognostic impact of histologically confirmed koilocytosis. In their study, p16INK4a expression predicted better cancer specific survival rates. Furthermore, p16INK4a can be useful in differentiate subtypes of PSCC. According Chaux \& Cubilla (2012), warty carcinomas tend to be p16INK4a positive, whereas giant condylomas and papillary and verrucous carcinomas are consistently negative.

Medical record analysis of 145 men with penile squamous cell carcinomas was performed to identify prognostic factors for lymph node involvement (Lopes et al. (1996)). The authors found that lymph node metastasis presents correlation with tumor thickness, lymphatic and vascular embolization. Interestingly, univariate analysis did not reached statistically significant values to pathologic stage of primary tumor, clinical lymph node stage $(\mathrm{cN})$, and histological grade. However, histological grade may be considered an important prognostic factor in penile squamous cell carcinoma. In accord with Cubilla AL. 2009 these prognostic factors are predictive to the nodal spread, metastasis and tumoral dissemination.

Currently, different methods are employed to grade Penile Squamous Cell Carcinomas. For instance, Akhter et al. (2011) uses the Broder's system as histological grade system in Squamous Cell Carcinoma. In the Broder's system Penile Squamous Cell Carcinomas is stratified in 4 grades levels based only in differentiation of the cells: Grade I (well differentiated) presenting $<25 \%$ undifferentiated cells; Grade II (Moderately differentiated) presenting $<50 \%$ undiffer- 
entiated cells; grade III (Poorly differentiated) presenting $<75 \%$ undifferentiated cells and grade IV (Anaplastic/Pleomorphic) $>75 \%$ undifferentiated cells. Cell anaplasia degrees are also pointed as common approach to determine Penile Squamous Cell Carcinomas grading (Mikuz et al. 2004; Slaton et al. 2001), absence of anaplasia (well differentiated cells), grade 1; grade 2 , moderately differentiated $(<50 \%$ anaplastic cells); and grade 3 , poorly differentiated $(>50 \%$ anaplastic cells). Cubilla et al. (2009) reported a method to grade Penile Squamous Cell Carcinomas. Carcinomas with a minimal deviation from normal/hyperplastic morphology of squamous epithelium were considered Grade 1 (extremely well-differentiated). Grade 3 are tumors showing any proportion of anaplastic cells, identified as solid sheets or irregular small aggregates, cords or nests of cells with little or no keratinization, high nuclear cytoplasmic ratio, thick nuclear membrane, nuclear pleomorphism, clumped chromatin, prominent nucleoli and numerous mitosis. Grade 2 is composed by remainder tumors. Grading both extremes of the spectrum is simple and reproducible.

In summary, Penile Squamous Cell Carcinomas represents an aggressive locoregional malignancy with dissemination process may occurring 20-40\% (Guimarães et al. 2009), a lethal disorder that often presents after significant delay (Barocas \& Chang 2010). Usually, death occurs within 2 years after initial diagnosis (Guimarães et al. 2009). Accurate evaluation of clinical stage, anatomical site, regional lymph nodes, and metastatic disease presents a pivotal role in treatment planning to predict the survival outcome (Barocas \& Chang, 2010).

\section{HPV}

Papillomaviruses are a family of pathogens that infect exclusively the epithelial tissues of amphibians, reptiles, birds and mammals (Franceschi, 2005). The viruses are grouped according to the anatomic site of infection and their preference for either cutaneous or mucosal squamous epithelium. The cutaneous types, or beta papillomaviruses, are usually found in the general population and cause common warts. In contrast, the alpha, or mucosotropic, papillomaviruses have been implicated in mucosal infections (Snow \& Laudadio, 2010; Vidal \& Gillison, 2008). The mucosotropic group of human papillomavirus comprises 15 species and infects the anogenital tract, upper aerodigestive tract and other head and neck mucosa (Chow et al., 2010). Because they are sexually transmitted and play important roles in diseases, these viruses have received much attention and research and clinical investment (Chow et al., 2010).

As molecular virology is depicted in details in another chapter, here we will only cover penile cancer-related aspects. Currently, over 200 HPV genotypes have been identified (Wang et al., 2012). HPVs with a high affinity for mucosal sites can be classified into non-oncogenic, or lowrisk, types or as potentially oncogenic, or high-risk, types. Mucosal and genital HPVs can be divided into low-risk (HPVs 6, 11, 40, 42, 43, 44, 54, 61, 70, 72, 81) and high-risk (HPVs 16, 18, $31,33,35,51,52$ ) types according to their presence in malignant lesions (Bosch et al., 2002; Muñoz et al., 2003).

The multiplicity of functions of the small papillomavirus oncoproteins, E5, E6 and E7, continues to be studied through last decades, although there are several mechanisms well 
established. Specifically, more than a dozen protein-protein interactions between E6 and cellular proteins have been shown (Villa et al., 2002). Taken into a carcinogenic point of view, E6 and E7 ORF are considered to play the most important roles, encoding for oncoproteins that allow viral replication and the immortalization and transformation of the epithelial cell that host the HPV DNA (Doorbar et al., 1991).

Proving the importance of p53 and pRb in cell cycle progression, the repression of HPV 16 E6 and E7 expression by dual shRNA transfection has been shown to be capable of restoring the p53 and pRb tumor suppressor pathways and activating apoptosis (Psyrri et al., 2009, Rampias et al., 2009). Thus, the demonstration of this tumor suppressor inactivation by the E6 and E7 HPV oncoproteins has provided a basic explanation for how the high-risk HPV types exert their oncogenic effects on cervical cells, and this explanation are under investigation to be related with other sites of HPV-infection. This is particularly important in penile cancerassociated HPV infection, whereas HPV16 seems to develop a pivotal role, and accounts for more than $60 \%$ of HPV-related tumors.

\section{HPV impact in squamous cell homeostasis}

Different from other viruses, HPV does not infect or replicate in antigen-presenting cells (APCs) of the epithelium nor induce cell lysis, which is a key escape mechanism to avoid that APC recognize and produce antigens derived from the virion, and alerts immune system. About more than $50 \%$ of infections present seroconversion in the patients, but the production of antibodies usually occurs only months after the initial infection (Vidal \& Gillison, 2008). The life cycle of papillomaviruses is closely tied to the epithelial differentiation process. Infection occurs exclusively in squamous epithelial cells with a preference for the keratinocyte stem cell as the initial target of HPV infection, which will allow the maintenance of viral replication (Vidal \& Gillison, 2008). The route of entry for HPV infection is microtraumas or small wounds in the skin or mucosal surface, which are particularly important in penile HPV-infection. These breaks in the epithelial surface allow the virus to access and persist in the nuclei of infected basal layer cells of the epithelium. Until now, no single receptor has been definitively identified and established as being responsible for HPV entry, although is believed that receptors closely related to wound healing might be preferential targets for HPV infection, such as $\alpha 6$ integrin and glycosamioglycan heparin (Vidal \& Gillison, 2008).

As most viruses, HPV uses the host cell DNA machinery to maintain the production of viral progeny. This mechanism of viral-induced cell growth is very well known and is analogous to other viruses that disrupt the control of cell growth (Hebner \& Laimins, 2006). Following cell division, as the basal cells divide into squamous epithelial cells, HPV establishes its DNA genome in the host cell nuclei, replicates and reaches a high copy number. Infected cells then leave the basal layer, migrate toward the suprabasal regions and begin to differentiate. In the basal layer phase, the HPV genome is maintained at a low copy number, providing a type of stock of viral DNA for further use in cell divisions. At the same time, 'early' viral genes (E5, E6 and E7) are expressed, resulting in enhanced proliferation of the infected cells and their 
lateral expansion, working to spread infection cells throughout epithelial tissue. While the basal cells and viral DNA divide, some daughter cells may be maintained in the basal layers, whereas other daughter cells move toward the upper layers of the epithelium and begin to differentiate. During this process in which the infected cells enter into the suprabasal layers, the viral genome replicates to a higher copy number; 'late' viral gene (L1 and L2) expression is initiated; and structural proteins, as such capsid proteins, are formed. Subsequently, virions are assembled and released as the upper layer of epithelium is shed (Fehrmann \& Laimins, 2003; Scheurer et al., 2005; Vidal \& Gillison, 2008).
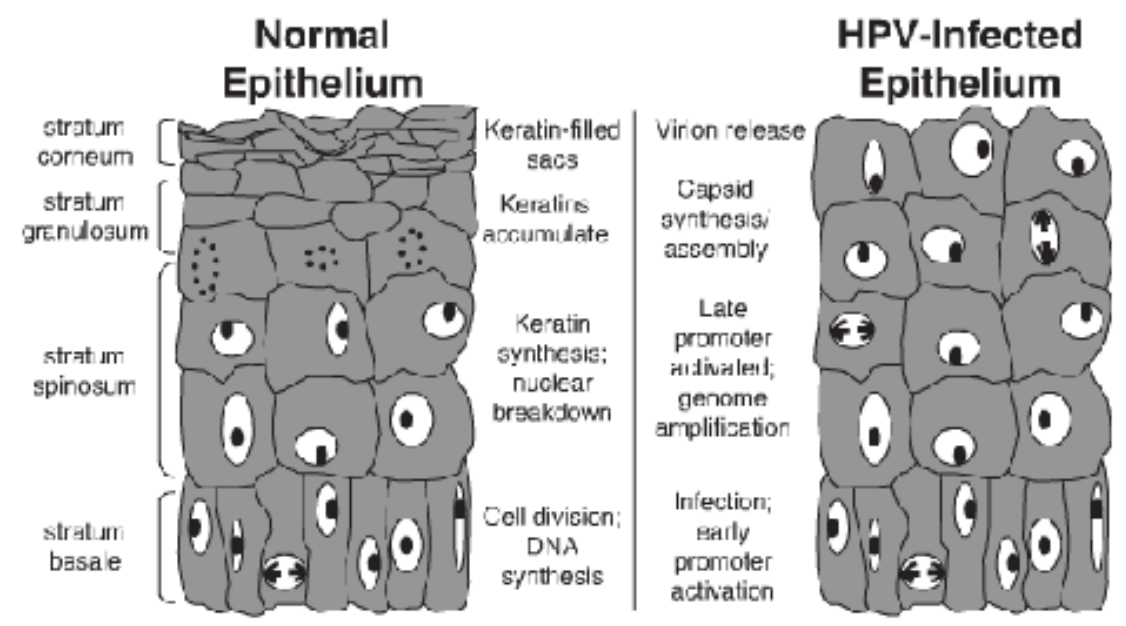

Figure 3. Representation of normal and HPV-infected epithelium according to the cellular differentiation and the differentiation-dependent viral functions (Adapted from Hebner \& Laimins, 2006).

This provides an important microenvironment for cellular growth aberrations, and is particularly important in penile pre-neoplastic lesions. Several authors have reported a higher level of HPV detection in PIN, when compared to penile cancer, open field for a HPV importance in the development of tissue growth abnormalities, leading to a soil field for carcinogenesis. In this model, HPV would be an important co-factor in penile pre-neoplastic development. Due to all of his effects in cell growth and lack of cell cycle control, the formation of lesions such as PIN associated to other important factors in penile carcinogenesis (genera hygiene, phimosis, chronic inflammation, high number of sexual partners).

\section{Prevalence of HPV infection in penile squamous cell carcinoma and histological considerations}

In contrast with the high prevalence of HPV infection in cervix carcinomas, which may be detected in almost $100 \%$ of the cases, in penile carcinomas the detection is considerably lower, 
although it stills an important in penile pathogenesis. According to the current evidences, penile cancer can follow 2 distinct etiologic pathways: one is related to environmental factors, such as phimosis, smoking, poor personal hygiene and chronic inflammation; and other one is the HPV-related penile cancer (Rubin et al., 2001; Cubilla et al., 2010). Several studies have highlighted the prevalence of HPV infection in penile cancer, with an average prevalence of $47 \%$ to $48 \%$ in more than 60 studies (Backes et al., 2009; Miralles-Guri et al., 2009). Differently from cervix cancer, in penile cancer the prevalence of HPV infection varies according to histological subtypes, being strongly prevalent in basaloid and warty carcinomas, and lesser prevalent in keratinizing variants, such as verrucous, papillary and usual carcinomas (Guimarães et al., 2011). Before understanding the relationship between HPV and specific histological subtypes, a basic knowledge of penile cancer histology is required.

Squamous cell carcinoma of the penis is currently divided in 12 subtypes. Each one of this subtypes shows distinctive outcomes, and this high number of subtypes makes its difficult to characterize the disease. About half of penile cancers are of the usual squamous histology, while the rest is divided through the special types.

Basaloid carcinomas: represent $4-10 \%$ of penile tumors. Macroscopically, these tumors show an ulcerative aspect, presenting as a solid, firm invasively neoplasm, with necrosis foci. Microscopically, they present a nesting pattern, with each nest presenting a solid or central necrotic nest (comedonecrosis). Keratinization can be observed, although not pathognomonic. Cells presents as small, basofilic, basaloid, spindle or pleomorphic, with abundance of mitotic and apoptotic figures. Perineural and vascular invasions are often seen.

Warty carcinomas: represent $7-10 \%$ of all cases. It can be described as verruciform tumors, with an exoendophytical appearance, although a rare non-invasive exophytic tumor may be found. Histologically, a classical condylomatous papilla is observed, with a arborescent pattern, a central fibrovascular core, and keratinized cells, with presence of superficial and deep pleomorphic koilocytosis. Different from giant condillomas, in warty carcinomas these cells are typically malignant. Also, as a differential diagnosis, low-risk HPV or negative p16INK4a status favors a condilloma diagnosis. Prognosis is often good, with no signs of nodal involvment, although it might be present in deep invasive warty carcinoma (Chaux \& Cubilla, 2012).

Verrucous carcinomas: represent 3-8\% of the cases. Macroscopically are classically characterized by exophytic, verrucoid white lesion, with a clear base separating them from the stroma. Microscopically, they are acanthotic, papillomatous neoplasms, with a high degree of diferentiation. As most well differentiated tumors, they have a good prognosis, only presenting metastasis when they present areas with poor differentiation. However, if it presents large areas of undifferentiation, the tumor is classified as a mixed verrucous carcinoma, as the classical verrucous carcinoma is a classicaly well differentiated tumor.

Papillary carcinoma: represent $9-10 \%$ of all cases. It is also a verruciform tumor, diagnosed after excluding the possibility of a verrucous or warty tumor. Macroscopically is observed as an exophytic large tumor, with a clear jagged interface with stroma. Microscopically, papillomatosis is observed and a low-grade histology is present. Different from verrucous carcinoma, 
acanthosis is not so prominent, and differently from warty carcinoma, there is no koilocytosis. They have an excellent prognosis with very infrequent metastasis.

Sarcomatoid carcinomas: correspond to 1-3\% of cases. Macroscopically, they are hemorrhagic and necrotic, or polypoid tumors. Microscopically, they can mimic several sarcomas, like leiomyosarcomas, osteosarcomas, or fibrosarcomas. They are observed as tumors with two different cellular presentations, with the presence of epithelial and spindle cells. They are typically located in glans, not in corpora cavernosa, and may present foci of associated penile intraepithelial neoplasia. Immunohistochemical stains with high-molecular-weight cytokeratins and p63.

Other mixed tumors are often rare, which makes very difficult to establish their relationship with HPV infection, and comprises several subtypes, such as Pseudohyperplastic Carcinoma, Carcinoma Cunilatum and Pseudoglandular Carcinoma.

As stated before, distinct pathological variants of PSCC are associated with an indolent behavior (eg, verrucous, warty and Buschke-Lowenstein condyloma) and other with more aggressive forms (eg, usual SCC, basaloid and papillary). For basaloid and warty carcinomas, the HPV-infections are present in $80-100 \%$ of all cases. It is important to remember that in situ SCC seems to be strongly related with HPV-infection (Kayes et al., 2007). Seems plausible then that HPV-infection is far more important as a co-factor that will prepare the soil for a neoplastic malignant transformation, due to the several pathways in which HPV-infection contributes. This is in accordance with the theory of two major pathways in penile cancer development, being one driven by factors such as poor hygiene, presence of phimosis, chronic inflammation, etc), and another one driven by high-risk HPV-infection (Rubin et al., 2001). As discussed above, this represents an astonishing opportunity for a new approach to prevent this disease, as HPV vaccination researches are under constant evolution. As a health problem, the prevention of HPV infection might be able to avoid the development of these subtypes of $\mathrm{HPV}$ in men, if the current knowledge of HPV-driven malignancy is right.

\section{HPV-status impact on outcome in penile carcinomas}

Although there are not many studies investigating a prognostic role for HPV-infection in penile carcinomas, some studies maintain HPV as a controversial factor, in terms either of survival, or local metastasis, and lymph node involvement. From the three more important studies, it is still unknown if HPV alone may have an impact in penile cancer's patients overall survival, as demonstrated in several other solid tumors, such those arising in oral cavity and oropharynx (Lont et al., 2006). In a study conducted by Cubilla et al. (2010), HPV-16 was the most prevalent genotype (72\% of all cases), followed by HPV-6 (9\%) and HPV-18 (6\%). The 16 and 18 genotype (high-risk HPV types) were proposed to be associated with aggressive variants of penile tumors, and to be associated with a poorer outcome in these patients. In several studies, the role of HPV infection in penile cancer could only be observed by indirect means, as the observation that HPV-infected PSCCs were those with more aggressive subtypes, as basaloid and warty tumors. So, it is believed that HPV-infection, specially related to HPV-16 and -18, 
represented a more aggressive subtype, with a worst survival when compared to HPVnegative PSCCs. But directly comparing HPV expression and survival curves, the most extensive study on high-risk HPV infection was carried out by Lont and colleagues, whom had demonstrated that penile tumors presenting high-risk HPV infection had a better outcome from those tumors where high-risk HPVs were not detected. Interestingly, HIV infection did not correlated (Lont et al., 2006).

\section{HPV vaccine}

In many countries, vaccines against some HPV types are administered to girls and young women with the goal of protecting them against HPV-induced cervical cancer (Villa et al., 2005; Muñoz et al., 2010). The introduction of HPV vaccines has also drawn more attention to the fact that HPV is associated not only with cervical cancer and genital warts but also with other tumors, such as head and neck and anogenital cancers (Zur Hausen, 2006).

Although the majority of HPV vaccine research has focused on cervical cancer, some vaccine developers have targeted other diseases related to different strains of HPV.

Emerging results from vaccine trials have suggested that some cross-protection is possible. Vaccines against cervical cancer also have the potential to prevent other cancers that are caused by the same types of HPV (Herrero et al., 2003, Kreimer et al., 2005), and half or more of anogenital cancers outside the cervix, including cancer of the vulva, vagina, penis, and anus (Daling et al., 2005, Gross \& Pfister 2004). Theoretically, these vaccines should also work against the same viruses at other anatomical sites, which would be of great value for the majority of the patients. Since different HPV-related diseases have share the same contamination basis (eg, HPV contamination in sexual act may happen in anogenital, cervical and even in head and neck areas. Also, almost all HPV-related tumors share individual at risk with the same behavior, and it is believed that this prevent potential directed to several organs could reduce the prevalence of several tumors simultaneously. If proven to do so, this approach would represent a major conceptual breakthrough, not only in prevention of these diseases, but equally importantly, by providing the 'missing link' in the chain of evidence for the final proof of HPV etiology in these tumors (Syrjänen, 2010).

\section{The HPV prophylactic vaccines}

The current HPV prophylactic vaccines are based on VLPs, with two prophylactic HPV vaccines being commercially available: the bivalent (HPV 16/18) vaccine Cervarix ${ }^{\circledR}($ GlaxoSmithKline, Middlesex, UK) and the quadrivalent (HPV 6/11/16/18) Gardasil ${ }^{\circledR}$ (Merck, NJ, USA). Licensed globally, these two vaccines have produced great expectations that they will prevent infections and tumors induced by different HPV types (Syrjänen, 2010).

The US Food and Drug Administration (FDA) approved Gardasil for females aged 9-26 in 2006. In October 2009, the FDA approved Cervarix for use in females aged 10-25 and approved 
Gardasil for use in males aged 9-26 to prevent genital warts and to prevent the spread of cervical cancer. Moreover, the FDA (2010 and 2010a) has proclaimed that the dosing and administration schedule should be $0.5 \mathrm{~mL}$ administered intramuscularly (preferably in a deltoid muscle) on a 3-dose schedule. The second dose should be administered 1 to 2 months later, and the third dose should be administered 6 months after the first dose.

Although clinical trials of Gardasil and Cervarix have been extremely promising, these first generation VLP vaccines may not be the ideal vaccine candidates, especially in already infected patients, and older men and women.

The most recent report from Quadrivalent Human Papillomavirus Vaccine presents important facts about immunization practices, and provides excellent results. The efficacy for prevention of HPV 6-, 11-, 16- and 18-related genital warts was $89.3 \%$, as a profilatic vaccine from those who have take 3 doses and was seronegative at day 1 . From males who have received only one dose, regardless of serology or previous infection was of $68.1 \%$. This efficacy was also confirmed by several other trials in female patients, with $>98 \%$ efficacy in preventing HPV 6-, 11-, 16- and 18-related grade 2 or 3 cervical intraepithelial neoplasia or adenocarcinoma in situ(CDC MMWR, 2011).

Another important issue in vaccination process is to determine who are the individuals in more risk populations, in order to a better efficacy, and a reduction of the high costs involved in the vaccine production and distribution. Based on incidence of HPV-infection between several groups, the probabilities of being infected, especially subtypes 16 and 18, are higher in men who have sex with men (MSM) group than in heterosexual men (Heiligenberg, 2010). Several diseases have a higher incidence in MSM group, such as anal intraepithelial neoplasia (AIN), anal cancers, and genital warts (Jin et al., 2007). Another important group which might be benefited by HPV immunization is the HIV-positive patients, although it is not clear whether the immunization could provide a long time antibody titers against HPV 6, 11, 16, and 18, and how immunossupressed patients would react to HPV4 vaccine, in terms of safety and adversely reactions. However, as HPV4 is not a live vaccine, it can be safely administered to person in the most highly risk, such as immunocompromised individuals (like HIV-positive, drug-driven immunossupression, or disease-related immunossupression).

Researchers are now actively working to better develop prophylactic HPV vaccines that may be effective against a broader range of HPV types and have a longer shelf life.

\section{The HPV therapeutic vaccines and its perspectives}

Immunotherapy offers an attractive alternative treatment strategy because it can address both the underlying HPV infection and the visible lesions. Moreover, immunotherapy can target all HPV-associated lesions, regardless of location, and induce long-lasting immunity, thus preventing recurrence (Chu, 2003; Stanley, 2012).

A judgment of whether therapeutic HPV vaccine candidates have a real effect on disease has been difficult because most trials have not been placebo-controlled, and more important, it 
stills not clear for how long these patients can maintain high levels of immune response, as they have been already infected. The vaccines have also shown, at best, limited efficacy in eradicating established tumors, although the fact that they have mostly been tested in advanced stage cancer patients with compromised immune systems may have limited their impact (Brinkman et al., 2005).

Perhaps the ideal HPV vaccine strategy calls for a vaccine that possesses both prophylactic and therapeutic properties. A chimeric vaccine of this type could both prevent new HPV infections and clear existing infections. Moreover, such a vaccine would benefit and could be administered to both sexually inexperienced young individuals and older individuals who already harbor HPV (Franceschi, 2005). Of course the costs of the rise of individuals been vaccinated needs to be estimated, in order to not turn HPV vaccine in an expensive waste of health budget. It is important to remember that although some groups are in risk group, not all individuals of this risk group will develop an HPV-related cancer. So, before implementing $\mathrm{HPV}$ vaccination to a wide range of patients, it needs to be better classified what populations should be included in vaccination process, and further develop new guidelines to better incorporate in this vaccination individuals that, even in risk groups, still have a higher risk in HPV-infection and spread. Opportunities for primary and secondary prevention should be assessed, including the use of HPV vaccines to prevent infection and therapeutic vaccines in the adjuvant setting for locoregional recurrence and distant disease (Marur et al. 2010). Combined with the fact that no therapeutic vaccines currently exist for other diseases, this goal makes therapeutic HPV vaccine development a challenging task.

The most recent report from Quadrivalent Human Papillomavirus Vaccine (HPV4) presents important facts about immunization practices, and provides excellent results. The efficacy for prevention of HPV 6-, 11-, 16- and 18-related genital warts was $89.3 \%$, as a profilatic vaccine from those who have take 3 doses and was seronegative at day 1 . From males who have received only one dose, regardless of serology or previous infection was of $68.1 \%$. This efficacy was also confirmed by several other trials in female patients, with $>98 \%$ efficacy in preventing HPV 6-, 11-, 16- and 18-related grade 2 or 3 cervical intraepithelial neoplasia or adenocarcinoma in situ (CDC MMWR, 2011).

\section{Final considerations}

Several aspects still remain to be discovered in the field of penile cancers and HPV infection, and although last decade researches were not able to define a causal role for HPV-infection, several progresses have being made in this matter. The genomic detection of HPV DNA, primarily in some subtypes of PSCCs, provides stronger support for a viral etiology in this disease, and corroborates the idea that there are at leas 2 main pathways in penile carcinogenesis, and one of them is closely related to HPV.

Targeted therapy for PSCCs now demands more predictive biomarkers, such as the HPV infection status and mutation status of crucial genes, which could contribute to personalized treatment for each individual and decrease the inherent morbidities. However, for a better 
understanding of whether the HPV status of tumors has real therapeutic implications in affecting the clinical outcome, upcoming clinical trials should be significantly standardized in their design and performed on PSCC, which have been adequately selected and classified with respect to the different penile carcinoma subtypes. Moreover, we suggest that a more defined consensus in the histological classification in PSCCs should be utilized to improve HPV detection and provides means to compare studies in different populations. This is highly remarkable as is now fully accepted that penile carcinogenesis is quite dependent of local characteristics, and varies worldwide.

We believe that the increasing effects of HPV vaccination in several cancers could help to reduce the number of new PSCC cases, especially in developing countries, with a lower income, and less educated individuals. Although detection of the true effects of HPV vaccination on cancer incidence will probably continue for several decades, monitoring the current effects of HPV vaccination is crucial, not only in cervical cancer, but also in penile cancer.

\section{Author details}

João Paulo Oliveira-Costa1,2, Giórgia Gobbi da Silveira², Danilo Figueiredo Soave ${ }^{2}$, Andrielle de Castilho Fernandes ${ }^{2}$, Lucinei Roberto Oliveira ${ }^{3}$, Alfredo Ribeiro-Silva ${ }^{2}$ and Fernando Augusto Soares ${ }^{1}$

1 AC Camargo Cancer Hospital - Antonio Prudente Cancer Care Center, Brazil

2 Ribeirão Preto Medical School, University of São Paulo, Brazil

3 Vale do Rio Verde University, Brazil

\section{References}

[1] Akhter M, Hossain S, Rahman QB, Molla MR. A study on histological grading of oral squamous cell carcinoma and its co-relationship with regional metastasis. J Oral Maxillofac Pathol. 2011 May;15(2):168-76. PubMed PMID: 22529575. Pubmed Central PMCID: PMC3329698. eng.

[2] Backes DM, Kurman RJ, Pimenta JM, Smith JS. Systematic review of human papillomavirus prevalence in invasive penile cancer. Cancer Causes Control. 2009 May; 20(4):449-57. PubMed PMID: 19082746. eng.

[3] Barocas DA, Chang SS. Penile cancer: clinical presentation, diagnosis, and staging. Urol Clin North Am. 2010 Aug;37(3):343-52. PubMed PMID: 20674691. eng. 
[4] Bleeker MC, Heideman DA, Snijders PJ, Horenblas S, Dillner J, Meijer CJ. Penile cancer: epidemiology, pathogenesis and prevention. World J Urol. 2009 Apr;27(2):141-50. PubMed PMID: 18607597. eng.

[5] Bosch FX, Lorincz A, MuÒoz N, Meijer CJ, Shah KV. The causal relation between human papillomavirus and cervical cancer. J Clin Pathol. 2002 Apr;55(4):244-65. PubMed PMID: 11919208. Pubmed Central PMCID: PMC1769629. eng.

[6] Brinkman JA, Caffrey AS, Muderspach LI, Roman LD, Kast WM. The impact of anti $\mathrm{HPV}$ vaccination on cervical cancer incidence and HPV induced cervical lesions: consequences for clinical management. Eur J Gynaecol Oncol. 2005;26(2):129-42. PubMed PMID: 15857016. eng.

[7] (CDC) CfDCaP. Recommendations on the use of quadrivalent human papillomavirus vaccine in males--Advisory Committee on Immunization Practices (ACIP), 2011. MMWR Morb Mortal Wkly Rep. 2011 Dec;60(50):1705-8. PubMed PMID: 22189893. eng.

[8] Chaux A, Cubilla AL. Advances in the pathology of penile carcinomas. Hum Pathol. 2012 Jun;43(6):771-89. PubMed PMID: 22595011. eng.

[9] Chaux A, Netto GJ, RodrÌguez IM, Barreto JE, Oertell J, Ocampos S, et al. Epidemiologic profile, sexual history, pathologic features, and human papillomavirus status of 103 patients with penile carcinoma. World J Urol. 2011 Nov. PubMed PMID: 22116602. Pubmed Central PMCID: PMC3292668. ENG.

[10] Chaux A, Velazquez EF, Algaba F, Ayala G, Cubilla AL. Developments in the pathology of penile squamous cell carcinomas. Urology. 2010 Aug;76(2 Suppl 1):S7-S14. PubMed PMID: 20691888. eng.

[11] Chow LT, Broker TR, Steinberg BM. The natural history of human papillomavirus infections of the mucosal epithelia. APMIS. 2010 Jun;118(6-7):422-49. PubMed PMID: 20553526. eng.

[12] Chu NR. Therapeutic vaccination for the treatment of mucosotropic human papillomavirus-associated disease. Expert Opin Biol Ther. 2003 Jun;3(3):477-86. PubMed PMID: 12783616. eng.

[13] Cubilla AL. The role of pathologic prognostic factors in squamous cell carcinoma of the penis. World J Urol. 2009 Apr;27(2):169-77. PubMed PMID: 18766352. eng.

[14] Cubilla AL, Lloveras B, Alejo M, Clavero O, Chaux A, Kasamatsu E, et al. The basaloid cell is the best tissue marker for human papillomavirus in invasive penile squamous cell carcinoma: a study of 202 cases from Paraguay. Am J Surg Pathol. 2010 Jan; 34(1):104-14. PubMed PMID: 20035150. eng.

[15] Cubilla AL, Reuter V, Velazquez E, Piris A, Saito S, Young RH. Histologic classification of penile carcinoma and its relation to outcome in 61 patients with primary resection. Int J Surg Pathol. 2001 Apr;9(2):111-20. PubMed PMID: 11484498. eng. 
[16] Daling JR, Madeleine MM, Johnson LG, Schwartz SM, Shera KA, Wurscher MA, et al. Penile cancer: importance of circumcision, human papillomavirus and smoking in in situ and invasive disease. Int J Cancer. 2005 Sep;116(4):606-16. PubMed PMID: 15825185. eng.

[17] Doorbar J, Ely S, Sterling J, McLean C, Crawford L. Specific interaction between HPV-16 E1-E4 and cytokeratins results in collapse of the epithelial cell intermediate filament network. Nature. 1991 Aug;352(6338):824-7. PubMed PMID: 1715519. eng.

[18] Epstein JH, Cubilla AL, Humphrey PA. Tumors of the prostate gland, seminal vesicles, penis, and scrotum. Atlas of tumor pathology. Washington, D.C.: Armed Forces Institute of Pathology; 2011. p. 405-612.

[19] Fehrmann F, Laimins LA. Human papillomaviruses: targeting differentiating epithelial cells for malignant transformation. Oncogene. 2003 Aug;22(33):5201-7. PubMed PMID: 12910257. eng.

[20] Food and Drug Administration (FDA) (2010). Licensure of Bivalent Human Papillomavirus Vaccine (HPV2, Cervarix) for Use in Females and Updated HPV Vaccination Recommendations from the Advisory Committee on Immunization Practices (ACIP). MMWR Morbidity and Mortality Weekly Report., 59, 20, pp. 626-629.

[21] Food and Drug Administration (FDA) (2010a). Licensure of Quadrivalent Human Papillomavirus Vaccine (HPV4, Gardasil) for Use in Males and Guidance from the Advisory Committee on Immunization Practices (ACIP). MMWR Morbidity and Mortality Weekly Report. , 59, 20, pp. 630-632.

[22] Franceschi S. The IARC commitment to cancer prevention: the example of papillomavirus and cervical cancer. Recent Results Cancer Res. 2005;166:277-97. PubMed PMID: 15648196. eng.

[23] Gross G, Pfister H. Role of human papillomavirus in penile cancer, penile intraepithelial squamous cell neoplasias and in genital warts. Med Microbiol Immunol. 2004 Feb;193(1):35-44. PubMed PMID: 12838415. eng.

[24] Guimarães GC, Cunha IW, Soares FA, Lopes A, Torres J, Chaux A, et al. Penile squamous cell carcinoma clinicopathological features, nodal metastasis and outcome in 333 cases. J Urol. 2009 Aug;182(2):528-34; discussion 34. PubMed PMID: 19524964. eng.

[25] Guimarães GC, Rocha RM, Zequi SC, Cunha IW, Soares FA. Penile cancer: epidemiology and treatment. Curr Oncol Rep. 2011 Jun;13(3):231-9. PubMed PMID: 21373986. eng.

[26] Gunia S, Erbersdobler A, Hakenberg OW, Koch S, May M. p16 ${ }^{\text {INK4a }}$ is a Marker of Good Prognosis for Primary Invasive Penile Squamous Cell Carcinoma: A Multi-Institutional Study. J Urol. 2012 Mar;187:899-907. 
[27] Hakenberg OW, Protzel C. Chemotherapy in penile cancer. Ther Adv Urol. 2012 Jun; 4(3):133-8. PubMed PMID: 22654965. Pubmed Central PMCID: PMC3361747. eng.

[28] Hebner CM, Laimins LA. Human papillomaviruses: basic mechanisms of pathogenesis and oncogenicity. Rev Med Virol. 20062006 Mar-Apr;16(2):83-97. PubMed PMID: 16287204. eng.

[29] Heiligenberg M; Michael KM; Kramer MA; Pawlita M, Prins M; Coutinho, Roel A, et al. Seroprevalence and Determinants of Eight High-Risk Human Papillomavirus Types in Homosexual Men, Heterosexual Men, and Women: A Population-Based Study in Amsterdam. Sexually Transmitted Diseases. 2010 Nov;37(11):672-80.

[30] Hernandez BY, Barnholtz-Sloan J, German RR, Giuliano A, Goodman MT, King JB, et al. Burden of invasive squamous cell carcinoma of the penis in the United States, 1998-2003. Cancer. 2008 Nov;113(10 Suppl):2883-91. PubMed PMID: 18980292. Pubmed Central PMCID: PMC2693711. eng.

[31] Herrero R, CastellsaguÈ X, Pawlita M, Lissowska J, Kee F, Balaram P, et al. Human papillomavirus and oral cancer: the International Agency for Research on Cancer multicenter study. J Natl Cancer Inst. 2003 Dec;95(23):1772-83. PubMed PMID: 14652239. eng.

[32] Jin F, Prestage GP, Kippax SC, Pell CM, Donovan B, Templeton DJ, et al. Risk factors for genital and anal warts in a prospective cohort of HIV-negative homosexual men: the HIM study. Sex Transm Dis. 2007 Jul;34(7):488-93. PubMed PMID: 17108849. eng.

[33] Kayes O, Ahmed HU, Arya M, Minhas S. Molecular and genetic pathways in penile cancer. Lancet Oncol. 2007 May;8(5):420-9. PubMed PMID: 17466899. eng.

[34] Kreimer AR, Clifford GM, Boyle P, Franceschi S. Human papillomavirus types in head and neck squamous cell carcinomas worldwide: a systematic review. Cancer Epidemiol Biomarkers Prev. 2005 Feb;14(2):467-75. PubMed PMID: 15734974. eng.

[35] Lont AP, Kroon BK, Horenblas S, Gallee MP, Berkhof J, Meijer CJ, et al. Presence of high-risk human papillomavirus DNA in penile carcinoma predicts favorable outcome in survival. Int J Cancer. 2006 Sep;119(5):1078-81. PubMed PMID: 16570278. eng.

[36] Lopes A, Bezerra AL, Pinto CA, Serrano SV, de MellO CA, Villa LL. p53 as a new prognostic factor for lymph node metastasis in penile carcinoma: analysis of 82 patients treated with amputation and bilateral lymphadenectomy. J Urol. 2002 Jul; 168(1):81-6. PubMed PMID: 12050497. eng.

[37] Lopes A, Hidalgo GS, Kowalski LP, Torloni H, Rossi BM, Fonseca FP. Prognostic factors in carcinoma of the penis: multivariate analysis of 145 patients treated with amputation and lymphadenectomy. J Urol. 1996 Nov;156(5):1637-42. PubMed PMID: 8863559. eng. 
[38] Marur S, D'Souza G, Westra WH, Forastiere AA. HPV-associated head and neck cancer: a virus-related cancer epidemic. Lancet Oncol. 2010 Aug;11(8):781-9. PubMed PMID: 20451455. eng.

[39] Mikuz G, Winstanley AM, Schulman CC, Debruyne FM, Parkinson CM. Handling and pathology reporting of circumcision and penectomy specimens. Eur Urol. 2004 Oct;46(4):434-9. PubMed PMID: 15363555. eng.

[40] Miralles-Guri C, Bruni L, Cubilla AL, CastellsaguÈ X, Bosch FX, de Sanjosè S. Human papillomavirus prevalence and type distribution in penile carcinoma. J Clin Pathol. 2009 Oct;62(10):870-8. PubMed PMID: 19706632. eng.

[41] Muñoz N, Bosch FX, de SanjosÈ S, Herrero R, CastellsaguÈ X, Shah KV, et al. Epidemiologic classification of human papillomavirus types associated with cervical cancer. N Engl J Med. 2003 Feb;348(6):518-27. PubMed PMID: 12571259. eng.

[42] Muñoz N, Kjaer SK, Sigurdsson K, Iversen OE, Hernandez-Avila M, Wheeler CM, et al. Impact of human papillomavirus (HPV)-6/11/16/18 vaccine on all HPV-associated genital diseases in young women. J Natl Cancer Inst. 2010 Mar;102(5):325-39. PubMed PMID: 20139221. eng.

[43] Novara G, Galfano A, De Marco V, Artibani W, Ficarra V. Prognostic factors in squamous cell carcinoma of the penis. Nat Clin Pract Urol. 2007 Mar;4(3):140-6. PubMed PMID: 17347658. eng.

[44] Pow-Sang MR, Ferreira U, Pow-Sang JM, Nardi AC, Destefano V. Epidemiology and natural history of penile cancer. Urology. 2010 Aug;76(2 Suppl 1):S2-6. PubMed PMID: 20691882. eng.

[45] Psyrri A, Gouveris P, Vermorken JB. Human papillomavirus-related head and neck tumors: clinical and research implication. Curr Opin Oncol. 2009 May;21(3):201-5. PubMed PMID: 19370803. eng.

[46] Rampias T, Sasaki C, Weinberger P, Psyrri A. E6 and e7 gene silencing and transformed phenotype of human papillomavirus 16-positive oropharyngeal cancer cells. J Natl Cancer Inst. 2009 Mar;101(6):412-23. PubMed PMID: 19276448. eng.

[47] Rubin MA, Kleter B, Zhou M, Ayala G, Cubilla AL, Quint WG, et al. Detection and typing of human papillomavirus DNA in penile carcinoma: evidence for multiple independent pathways of penile carcinogenesis. Am J Pathol. 2001 Oct;159(4):1211-8. PubMed PMID: 11583947. Pubmed Central PMCID: PMC1850485. eng.

[48] Scheurer ME, Tortolero-Luna G, Adler-Storthz K. Human papillomavirus infection: biology, epidemiology, and prevention. Int J Gynecol Cancer. 20052005 Sep-Oct; 15(5):727-46. PubMed PMID: 16174218. eng.

[49] Slaton JW, Morgenstern N, Levy DA, Santos MW, Tamboli P, Ro JY, et al. Tumor stage, vascular invasion and the percentage of poorly differentiated cancer: inde- 
pendent prognosticators for inguinal lymph node metastasis in penile squamous cancer. J Urol. 2001 Apr;165(4):1138-42. PubMed PMID: 11257655. eng.

[50] Snow AN, Laudadio J. Human papillomavirus detection in head and neck squamous cell carcinomas. Adv Anat Pathol. 2010 Nov;17(6):394-403. PubMed PMID: 20966645. eng.

[51] Stankiewicz E, Ng M, Cuzick J, Mesher D, Watkin N, Lam W, et al. The prognostic value of Ki-67 expression in penile squamous cell carcinoma. J Clin Pathol. 2012 Jun; 65(6):534-7. PubMed PMID: 22447920. eng.

[52] Stanley M. Chapter 17: Genital human papillomavirus infections--current and prospective therapies. J Natl Cancer Inst Monogr. 2003 (31):117-24. PubMed PMID: 12807955. eng.

[53] Stanley MA. Genital human papillomavirus infections: current and prospective therapies. J Gen Virol. 2012 Apr;93(Pt 4):681-91. PubMed PMID: 22323530. eng.

[54] Syed S, Eng TY, Thomas CR, Thompson IM, Weiss GR. Current issues in the management of advanced squamous cell carcinoma of the penis. Urol Oncol. 20032003 NovDec;21(6):431-8. PubMed PMID: 14693269. eng.

[55] Syrjänen S. The role of human papillomavirus infection in head and neck cancers. Ann Oncol. 2010 Oct;21 Suppl 7:vii243-5. PubMed PMID: 20943622. eng.

[56] Velazquez EF, Amin MB, Epstein JI, Grignon DJ, Humphrey PA, Pettaway CA, et al. Protocol for the examination of specimens from patients with carcinoma of the penis. Arch Pathol Lab Med. 2010 Jun;134(6):923-9. PubMed PMID: 20524869. eng.

[57] Velazquez EF, Soskin A, Bock A, Codas R, Cai G, Barreto JE, et al. Epithelial abnormalities and precancerous lesions of anterior urethra in patients with penile carcinoma: a report of 89 cases. Mod Pathol. 2005 Jul;18(7):917-23. PubMed PMID: 15920559. eng.

[58] Vidal L, Gillison ML. Human papillomavirus in HNSCC: recognition of a distinct disease type. Hematol Oncol Clin North Am. 2008 Dec;22(6):1125-42, vii. PubMed PMID: 19010263. eng.

[59] Villa LL, Bernard HU, Kast M, Hildesheim A, Amestoy G, Franco EL. Past, present, and future of HPV research: highlights from the 19th International Papillomavirus Conference-HPV2001. Virus Res. 2002 Nov;89(2):163-73. PubMed PMID: 12445656. eng.

[60] Villa LL, Costa RL, Petta CA, Andrade RP, Ault KA, Giuliano AR, et al. Prophylactic quadrivalent human papillomavirus (types 6, 11, 16, and 18) L1 virus-like particle vaccine in young women: a randomised double-blind placebo-controlled multicentre phase II efficacy trial. Lancet Oncol. 2005 May;6(5):271-8. PubMed PMID: 15863374. eng. 
[61] Wang S, Wei H, Wang N, Zhang S, Zhang Y, Ruan Q, et al. The prevalence and role of human papillomavirus genotypes in primary cervical screening in the northeast of China. BMC Cancer. 2012 May;12(160).

[62] Zur Hausen, H. (2006). Infections causing human cancer. Weinheim (Germany): Wiley-VCH Verlag, pp. 145-243. 